\title{
On variational inequality, fixed point and generalized mixed equilibrium problems
}

\author{
Dong Feng $\mathrm{Li}^{1 *}$ and Juan Zhao ${ }^{2}$
}

\author{
"Correspondence: sylidf@yeah.net \\ 'School of Information Engineering, \\ North China University of Water \\ Resources and Electric Power, \\ Zhengzhou, Henan 450011, China \\ Full list of author information is \\ available at the end of the article
}

\begin{abstract}
In this article, variational inequality, fixed point, and generalized mixed equilibrium problems are investigated based on an extragradient iterative algorithm. Weak convergence of the extragradient iterative algorithm is obtained in Hilbert spaces.
\end{abstract}

Keywords: fixed point; equilibrium problem; monotone mapping; nonexpansive mapping; projection

\section{Introduction}

In this paper, we always assume that $H$ is a real Hilbert space with the inner product $\langle\cdot, \cdot\rangle$ and the norm $\|\cdot\|$, and $C$ is a nonempty, closed, and convex subset of $H$. $\mathbb{R}$ is denoted by the set of real numbers. Let $F$ be a bifunction of $C \times C$ into $\mathbb{R}$. Consider the problem: find a $p$ such that

$$
F(p, y) \geq 0, \quad \forall y \in C
$$

In this paper, the solution set of the problem is denoted by $\operatorname{EP}(F)$, i.e.,

$$
\operatorname{EP}(F)=\{p \in C: F(p, y) \geq 0, \forall y \in C\} .
$$

The above problem is first introduced by Ky Fan [1]. In the sense of Blum and Oettli [2], the Ky Fan problem is also called an equilibrium problem.

Recently, the 'so-called' generalized mixed equilibrium problem has been investigated by many authors: The generalized mixed equilibrium problem is to find $p \in C$ such that

$$
F(p, y)+\langle A p, y-p\rangle+\varphi(y)-\varphi(p) \geq 0, \quad \forall y \in C,
$$

where $\varphi: C \rightarrow \mathbb{R}$ is a real valued function and $A: C \rightarrow H$ is mapping. We use $\operatorname{GMEP}(F$, $A, \varphi)$ to denote the solution set of the equilibrium problem. That is,

$$
\operatorname{GMEP}(F, A, \varphi):=\{p \in C: F(p, y)+\langle A p, y-p\rangle+\varphi(y)-\varphi(z) \geq 0, \forall y \in C\}
$$

Next, we give some special cases.

\section{Springer}

O2014 Li and Zhao; licensee Springer. This is an Open Access article distributed under the terms of the Creative Commons Attribution License (http://creativecommons.org/licenses/by/2.0), which permits unrestricted use, distribution, and reproduction in any medium, provided the original work is properly cited. 
If $A=0$, then the problem (1.2) is equivalent to find $p \in C$ such that

$$
F(p, y)+\varphi(y)-\varphi(z) \geq 0, \quad \forall y \in C,
$$

which is called the mixed equilibrium problem.

If $F=0$, then the problem (1.2) is equivalent to find $p \in C$ such that

$$
\langle A p, y-p\rangle+\varphi(y)-\varphi(z) \geq 0, \quad \forall y \in C,
$$

which is called the mixed variational inequality of Browder type.

If $\varphi=0$, then the problem (1.2) is equivalent to find $p \in C$ such that

$$
F(p, y)+\langle A p, y-p\rangle \geq 0, \quad \forall y \in C,
$$

which is called the generalized equilibrium problem.

If $A=0$ and $\varphi=0$, then the problem (1.2) is equivalent to (1.1).

For solving the above equilibrium problems, let us assume that the bifunction $F: C \times$ $C \rightarrow \mathbb{R}$ satisfies the following conditions:

(A1) $F(x, x)=0, \forall x \in C$;

(A2) $F$ is monotone, i.e., $F(x, y)+F(y, x) \leq 0, \forall x, y \in C$;

(A3)

$$
\limsup _{t \downarrow 0} F(t z+(1-t) x, y) \leq F(x, y), \quad \forall x, y, z \in C ;
$$

(A4) for each $x \in C, y \mapsto F(x, y)$ is convex and weakly lower semicontinuous.

Equilibrium problems have intensively been studied. It has been shown that equilibrium problems cover fixed point problems, variational inequality problems, inclusion problems, saddle problems, complementarity problem, minimization problem, and Nash equilibrium problem; see [1-20] and the references therein.

Let $S: C \rightarrow C$ be a mapping. In this paper, we use $F(S)$ to stand for the set of fixed points. Recall that the mapping $S$ is said to be nonexpansive if

$$
\|S x-S y\| \leq\|x-y\|, \quad \forall x, y \in C .
$$

$S$ is said to be $\kappa$-strictly pseudocontractive if there exists a constant $\kappa \in[0,1)$ such that

$$
\|S x-S y\|^{2} \leq\|x-y\|^{2}+\kappa\|x-y-S x+S y\|^{2}, \quad \forall x, y \in C .
$$

It is clear that the class of $\kappa$-strictly pseudocontractive includes the class of nonexpansive mappings as a special case. The class of $\kappa$-strictly pseudocontractive mappings was introduced by Browder and Petryshyn [21]; for existence and approximation of fixed points of the class of mappings, see [22-29] and the references therein.

Let $A: C \rightarrow H$ be a mapping. Recall that $A$ is said to be monotone if

$$
\langle A x-A y, x-y\rangle \geq 0, \quad \forall x, y \in C .
$$


$A$ is said to be $\kappa$-inverse strongly monotone if there exists a constant $\alpha>0$ such that

$$
\langle A x-A y, x-y\rangle \geq \kappa\|A x-A y\|^{2}, \quad \forall x, y \in C .
$$

It is clear that the $\kappa$-inverse being strongly monotone is monotone and Lipschitz continuous.

A set-valued mapping $T: H \rightarrow 2^{H}$ is said to be monotone if, for all $x, y \in H, f \in T x$ and $g \in T y$ imply $\langle x-y, f-g\rangle>0$. A monotone mapping $T: H \rightarrow 2^{H}$ is maximal if the graph $G(T)$ of $T$ is not properly contained in the graph of any other monotone mapping. It is well known that a monotone mapping $T$ is maximal if and only if, for any $(x, f) \in H \times H$, $\langle x-y, f-g\rangle \geq 0$ for all $(y, g) \in G(T)$ implies $f \in T x$. The class of monotone operators is one of the most important classes of operators. Within the past several decades, many authors have been devoting their efforts to the studies of the existence and convergence of zero points for maximal monotone operators.

Let $F(x, y)=\langle A x, y-x\rangle, \forall x, y \in C$. We see that the problem (1.1) is reduced to the following classical variational inequality. Find $x \in C$ such that

$$
\langle A x, y-x\rangle \geq 0, \quad \forall y \in C .
$$

It is well known that $x \in C$ is a solution to (1.6) if and only if $x$ is a fixed point of the mapping $P_{C}(I-\rho A)$, where $\rho>0$ is a constant, and $I$ is the identity mapping. If $C$ is bounded, closed, and convex, then the solution set of the variational inequality (1.6) is nonempty.

In order to prove our main results, we need the following lemmas.

Lemma 1.1 [21] Let $S: C \rightarrow C$ be a $\kappa$-strictly pseudocontractive mapping. Define $S_{t}: C \rightarrow$ $C$ by $S_{t} x=t x+(1-t) S x$ for each $x \in C$. Then, as $t \in[\kappa, 1), S_{t}$ is nonexpansive such that $F\left(S_{t}\right)=F(S)$.

Lemma 1.2 [2] Let $C$ be a nonempty, closed, and convex subset of $H$, and $F: C \times C \rightarrow \mathbb{R} a$ bifunction satisfying (A1)-(A4). Then, for any $r>0$ and $x \in H$, there exists $z \in C$ such that

$$
F(z, y)+\frac{1}{r}\langle y-z, z-x\rangle \geq 0, \quad \forall y \in C .
$$

Further, define

$$
T_{r} x=\left\{z \in C: F(z, y)+\frac{1}{r}\langle y-z, z-x\rangle \geq 0, \forall y \in C\right\}
$$

for all $r>0$ and $x \in H$. Then the following hold:

(a) $T_{r}$ is single-valued;

(b) $T_{r}$ is firmly nonexpansive, i.e., for any $x, y \in H$,

$$
\left\|T_{r} x-T_{r} y\right\|^{2} \leq\left\langle T_{r} x-T_{r} y, x-y\right\rangle
$$

(c) $F\left(T_{r}\right)=\mathrm{EP}(F)$;

(d) $\mathrm{EP}(F)$ is closed and convex. 
Lemma 1.3 [30] Let $A$ be a monotone mapping of $C$ into $H$ and $N_{C} v$ the normal cone to $C$ at $v \in C$, i.e.,

$$
N_{C} v=\{w \in H:\langle v-u, w\rangle \geq 0, \forall u \in C\}
$$

and define a mapping $T$ on $C$ by

$$
T v= \begin{cases}A v+N_{C} v, & v \in C, \\ \varnothing, & v \notin C .\end{cases}
$$

Then $T$ is maximal monotone and $0 \in T v$ if and only if $\langle A v, u-v\rangle \geq 0$ for all $u \in C$.

Lemma 1.4 [31] Let $\left\{a_{n}\right\}_{n=1}^{\infty}$ be real numbers in $[0,1]$ such that $\sum_{n=1}^{\infty} a_{n}=1$. Then we have the following:

$$
\left\|\sum_{i=1}^{\infty} a_{i} x_{i}\right\|^{2} \leq \sum_{i=1}^{\infty} a_{i}\left\|x_{i}\right\|^{2}
$$

for any given bounded sequence $\left\{x_{n}\right\}_{n=1}^{\infty}$ in $H$.

Lemma 1.5 [32] Let $0<p \leq t_{n} \leq q<1$ for all $n \geq 1$. Suppose that $\left\{x_{n}\right\}$ and $\left\{y_{n}\right\}$ are sequences in $H$ such that

$$
\limsup _{n \rightarrow \infty}\left\|x_{n}\right\| \leq d, \quad \limsup _{n \rightarrow \infty}\left\|y_{n}\right\| \leq d
$$

and

$$
\lim _{n \rightarrow \infty}\left\|t_{n} x_{n}+\left(1-t_{n}\right) y_{n}\right\|=d
$$

hold for some $r \geq 0$. Then $\lim _{n \rightarrow \infty}\left\|x_{n}-y_{n}\right\|=0$.

Lemma 1.6 [21] Let $C$ be a nonempty, closed, and convex subset of $H$, and $S: C \rightarrow C$ a strictly pseudocontractive mapping. If $\left\{x_{n}\right\}$ is a sequence in $C$ such that $x_{n} \rightarrow x$ and $\lim _{n \rightarrow \infty}\left\|x_{n}-S x_{n}\right\|=0$, then $x=S x$.

Lemma 1.7 [33] Let $\left\{a_{n}\right\},\left\{b_{n}\right\}$, and $\left\{c_{n}\right\}$ be three nonnegative sequences satisfying the following condition:

$$
a_{n+1} \leq\left(1+b_{n}\right) a_{n}+c_{n}, \quad \forall n \geq n_{0}
$$

where $n_{0}$ is some nonnegative integer, $\sum_{n=1}^{\infty} b_{n}<\infty$ and $\sum_{n=1}^{\infty} c_{n}<\infty$. Then the limit $\lim _{n \rightarrow \infty} a_{n}$ exists.

\section{Main results}

Theorem 2.1 Let $C$ be a nonempty, closed, and convex subset of $H, S: C \rightarrow C$ a $\kappa$-strictly pseudocontractive mapping with a nonempty fixed point set, and $A: C \rightarrow H$ an L-Lipschitz 
continuous and monotone mapping. Let $F_{m}$ be a bifunction from $C \times C$ to $\mathbb{R}$ which satisfies (A1)-(A4), $B_{m}: C \rightarrow H$ a continuous and monotone mapping, $\varphi_{m}: C \rightarrow \mathbb{R}$ a lower semicontinuous and convex function for each $m \geq 1$. Assume that $\mathcal{F}:=\bigcap_{m=1}^{\infty} \operatorname{GMEP}\left(F_{m}, B_{m}, \varphi_{m}\right) \cap$ $\operatorname{VI}(C, A) \cap F(S)$ is not empty. Let $\left\{\alpha_{n}\right\},\left\{\beta_{n}\right\}$, and $\left\{\delta_{n, m}\right\}$ be real number sequences in $(0,1)$. Let $\left\{\lambda_{n}\right\},\left\{r_{n, m}\right\}$ be positive real number sequences. Let $\left\{x_{n}\right\}$ be a sequence generated in the following manner:

$$
\left\{\begin{array}{l}
x_{1} \in H, \\
x_{n+1}=\alpha_{n} x_{n}+\left(1-\alpha_{n}\right)\left(\beta_{n} I+\left(1-\beta_{n}\right) S\right) \operatorname{Proj}_{C}\left(\sum_{m=1}^{\infty} \delta_{n, m} z_{n, m}-\lambda_{n} A y_{n}\right), \quad n \geq 1, \\
y_{n}=\operatorname{Proj}_{C}\left(\sum_{m=1}^{\infty} \delta_{n, m} z_{n, m}-\lambda \lambda_{n} A \sum_{m=1}^{\infty} \delta_{n, m} z_{n, m}\right),
\end{array}\right.
$$

where $z_{n, m}$ is such that

$$
F_{m}\left(z_{n, m}, z\right)+\left\langle B_{m} z_{n, m}, z-z_{n, m}\right\rangle+\varphi_{m}(z)-\varphi_{m}\left(z_{n, m}\right)+\frac{1}{r_{n, m}}\left\langle z-z_{n, m}, z_{n, m}-x_{n}\right\rangle \geq 0, \quad \forall z \in C .
$$

Assume that $\left\{\alpha_{n}\right\},\left\{\beta_{n}\right\},\left\{\delta_{n, m}\right\},\left\{\lambda_{n}\right\},\left\{r_{n, m}\right\}$ satisfy the following restrictions:

(a) $0<a \leq \alpha_{n} \leq b<1$;

(b) $\kappa \leq \beta_{n} \leq c<1$;

(c) $\sum_{m=1}^{\infty} \delta_{n, m}=1$, and $0<d \leq \delta_{n, m} \leq 1$;

(d) $\liminf _{n \rightarrow \infty} r_{n, m}>0$ and $e \leq \lambda_{n} \leq f$, where e, $f \in(0,1 / L)$.

Then the sequence $\left\{x_{n}\right\}$ weakly converges to some point $\bar{x} \in \mathcal{F}$.

Proof The proof is split into five steps.

Step 1 . Show that the sequence $\left\{x_{n}\right\}$ is bounded.

Define $G_{m}(p, y)=F_{m}(p, y)+\left\langle B_{m} p, y-p\right\rangle+\varphi_{m}(y)-\varphi_{m}(p), \forall p, y \in C$. Next, we prove that the bifunction $G_{m}$ satisfies the conditions (A1)-(A4). Therefore, generalized mixed equilibrium problem is equivalent to the following equilibrium problem: find $p \in C$ such that $G_{m}(p, y) \geq 0, \forall y \in C$. It is clear that $G_{m}$ satisfies (A1). Next, we prove $G_{m}$ is monotone. Since $B_{m}$ is a continuous and monotone operator, we find from the definition of $G$ that

$$
\begin{aligned}
G_{m}(y, z)+G_{m}(z, y)= & F_{m}(y, z)+\left\langle B_{m} y, z-y\right\rangle+\varphi_{m}(z)-\varphi_{m}(y)+F_{m}(z, y) \\
& +\left\langle B_{m} z, y-z\right\rangle+\varphi_{m}(y)-\varphi_{m}(z) \\
= & F_{m}(z, y)+F_{m}(y, z)+\left\langle B_{m} z, y-z\right\rangle+\left\langle B_{m} y, z-y\right\rangle \\
\leq & \left\langle B_{m} z-B_{m} y, y-z\right\rangle \\
\leq & 0 .
\end{aligned}
$$

Next, we show $G_{m}$ satisfies (A3), that is,

$$
\limsup _{t \downarrow 0} G_{m}(t z+(1-t) x, y) \leq G_{m}(x, y), \quad \forall x, y, z \in C .
$$

Since $B_{m}$ is continuous and $\varphi_{m}$ is lower semicontinuous, we have

$$
\begin{aligned}
\limsup _{t \downarrow 0} G_{m}(t z+(1-t) x, y)= & \limsup _{t \downarrow 0} F_{m}(t z+(1-t) x, y) \\
& +\limsup _{t \downarrow 0}\left\langle B_{m}(t z+(1-t) x), y-(t z+(1-t) x)\right\rangle
\end{aligned}
$$




$$
\begin{aligned}
& +\limsup _{t \downarrow 0}\left(\varphi_{m}(y)-\varphi_{m}(t z+(1-t) x)\right) \\
\leq & F_{m}(x, y)+\left\langle B_{m} x, y-x\right\rangle+\varphi_{m}(y)-\varphi_{m}(x) \\
= & G_{m}(x, y) .
\end{aligned}
$$

Next, we show that, for each $x \in C, y \mapsto G_{m}(x, y)$ is a convex and lower semicontinuous. For each $x \in C$, for all $t \in(0,1)$ and for all $y, z \in C$, since $F_{m}$ satisfies (A4) and $\varphi_{m}$ is convex, we have

$$
\begin{aligned}
G_{m} & (x, t y+(1-t) z) \\
= & F_{m}(x, t y+(1-t) z)+\left\langle B_{m} x, t y+(1-t) z-x\right\rangle+\varphi_{m}(t y+(1-t) z)-\varphi_{m}(x) \\
\leq & t\left(F_{m}(x, y)+\left\langle B_{m} x, y-x\right\rangle+\varphi_{m}(y)-\varphi_{m}(x)\right) \\
\quad & \quad+(1-t)\left(F_{m}(x, z)+\left\langle B_{m} x, z-x\right\rangle+\varphi_{m}(z)-\varphi_{m}(x)\right) \\
= & t G_{m}(x, y)+(1-t) G_{m}(x, z) .
\end{aligned}
$$

Thus, $y \mapsto G_{m}(x, y)$ is convex. Similarly, we find that $y \mapsto G_{m}(x, y)$ is also lower semicontinuous. Put $u_{n}=\operatorname{Proj}_{C}\left(\sum_{m=1}^{N} \delta_{n, m} z_{n, m}-\lambda_{n} A y_{n}\right)$ and $v_{n}=\sum_{m=1}^{N} \delta_{n, m} z_{n, m}$. Letting $p \in \mathcal{F}$, we see that

$$
\begin{aligned}
\left\|u_{n}-p\right\|^{2} \leq & \left\|v_{n}-\lambda_{n} A y_{n}-p\right\|^{2}-\left\|v_{n}-\lambda_{n} A y_{n}-u_{n}\right\|^{2} \\
= & \left\|v_{n}-p\right\|^{2}-\left\|v_{n}-u_{n}\right\|^{2}+2 \lambda_{n}\left(\left\langle A y_{n}-A p, p-y_{n}\right\rangle+\left\langle A p, p-y_{n}\right\rangle\right. \\
& \left.+\left\langle A y_{n}, y_{n}-u_{n}\right\rangle\right) \\
\leq & \left\|v_{n}-p\right\|^{2}-\left\|v_{n}-y_{n}\right\|^{2}-\left\|y_{n}-u_{n}\right\|^{2}+2\left\langle v_{n}-\lambda_{n} A y_{n}-y_{n}, u_{n}-y_{n}\right\rangle .
\end{aligned}
$$

Notice that $A$ is $L$-Lipschitz continuous and $y_{n}=\operatorname{Proj}_{C}\left(v_{n}-\lambda_{n} A v_{n}\right)$. It follows that

$$
\left\langle v_{n}-\lambda_{n} A y_{n}-y_{n}, u_{n}-y_{n}\right\rangle \leq \lambda_{n} L\left\|v_{n}-y_{n}\right\|\left\|u_{n}-y_{n}\right\| .
$$

It follows that

$$
\left\|u_{n}-p\right\|^{2} \leq\left\|v_{n}-p\right\|^{2}+\left(\lambda_{n}^{2} L^{2}-1\right)\left\|v_{n}-y_{n}\right\|^{2} .
$$

On the other hand, we have

$$
\begin{aligned}
\left\|v_{n}-p\right\|^{2} & \leq\left\|\sum_{m=1}^{\infty} \delta_{n, m} z_{n, m}-p\right\|^{2} \\
& \leq \sum_{m=1}^{\infty} \delta_{n, m}\left\|T_{r_{n, m}} x_{n}-p\right\|^{2} \\
& \leq\left\|x_{n}-p\right\|^{2},
\end{aligned}
$$

where $T_{r_{n, m}}=\left\{z \in C: G_{m}(z, y)+\frac{1}{r}\langle y-z, z-x\rangle \geq 0, \forall y \in C\right\}$. Substituting (2.2) into (2.1), we obtain

$$
\left\|u_{n}-p\right\|^{2} \leq\left\|x_{n}-p\right\|^{2}+\left(\lambda_{n}^{2} L^{2}-1\right)\left\|v_{n}-y_{n}\right\|^{2} .
$$


Putting $S_{n}=\beta_{n} I+\left(1-\beta_{n}\right) S$, we find from Lemma 1.1 that $S_{n}$ is nonexpansive and $F\left(S_{n}\right)=$ $F(S)$. It follows that

$$
\begin{aligned}
\left\|x_{n+1}-p\right\|^{2} & \leq \alpha_{n}\left\|x_{n}-p\right\|^{2}+\left(1-\alpha_{n}\right)\left\|S_{n} u_{n}-p\right\|^{2} \\
& \leq \alpha_{n}\left\|x_{n}-p\right\|^{2}+\left(1-\alpha_{n}\right)\left\|u_{n}-p\right\|^{2} \\
& \leq \alpha_{n}\left\|x_{n}-p\right\|^{2}+\left(1-\alpha_{n}\right)\left(\left\|x_{n}-p\right\|^{2}+\left(\lambda_{n}^{2} L^{2}-1\right)\left\|v_{n}-y_{n}\right\|^{2}\right) \\
& \leq\left\|x_{n}-p\right\|^{2}+\left(1-\alpha_{n}\right)\left(\lambda_{n}^{2} L^{2}-1\right)\left\|v_{n}-y_{n}\right\|^{2} \\
& \leq\left\|x_{n}-p\right\|^{2} .
\end{aligned}
$$

It follows from Lemma 1.7 that the $\lim _{n \rightarrow \infty}\left\|x_{n}-p\right\|$ exists. This shows that $\left\{x_{n}\right\}$ is bounded. Since $\left\{x_{n}\right\}$ is bounded, we may assume that a subsequence $\left\{x_{n_{i}}\right\}$ of $\left\{x_{n}\right\}$ converges weakly to $\xi$.

Step 2. Show that $\xi \in \operatorname{VI}(C, A)$

From (2.3), we find that $\beta_{n}\left(1-\lambda_{n}^{2} L^{2}\right)\left\|v_{n}-y_{n}\right\|^{2} \leq\left\|x_{n}-p\right\|^{2}-\left\|x_{n+1}-p\right\|^{2}$. In view of the restrictions (b) and (d), we see that $\lim _{n \rightarrow \infty}\left\|v_{n}-y_{n}\right\|=0$. Since $\left\|y_{n}-u_{n}\right\| \leq \lambda L\left\|v_{n}-y_{n}\right\|$, we have that $\lim _{n \rightarrow \infty}\left\|y_{n}-u_{n}\right\|=0$. It follows that

$$
\lim _{n \rightarrow \infty}\left\|v_{n}-u_{n}\right\|=0
$$

Notice that

$$
\begin{aligned}
\left\|z_{n, m}-p\right\|^{2} & =\left\|T_{r_{n, m}} x_{n}-T_{r_{n, m}} p\right\|^{2} \\
& \leq\left\langle T_{r_{n, m} x_{n}}-T_{r_{n, m}} p, x_{n}-p\right\rangle \\
& =\frac{1}{2}\left(\left\|z_{n, m}-p\right\|^{2}+\left\|x_{n}-p\right\|^{2}-\left\|z_{n, m}-x_{n}\right\|^{2}\right) .
\end{aligned}
$$

This implies that $\left\|z_{n, m}-p\right\|^{2} \leq\left\|x_{n}-p\right\|^{2}-\left\|z_{n, m}-x_{n}\right\|^{2}$. Since $v_{n}=\sum_{m=1}^{\infty} \delta_{n, m} z_{n, m}$, where $\sum_{m=1}^{\infty} \delta_{n, m}=1$, we find that

$$
\begin{aligned}
\left\|v_{n}-p\right\|^{2} & \leq \sum_{m=1}^{\infty} \delta_{n, m}\left\|z_{n, m}-p\right\|^{2} \\
& \leq\left\|x_{n}-p\right\|^{2}-\sum_{m=1}^{\infty} \delta_{n, m}\left\|z_{n, m}-x_{n}\right\|^{2} .
\end{aligned}
$$

It follows that

$$
\begin{aligned}
\left\|x_{n+1}-p\right\|^{2} & \leq \alpha_{n}\left\|x_{n}-p\right\|^{2}+\left(1-\alpha_{n}\right)\left\|S_{n} u_{n}-p\right\|^{2} \\
& \leq \alpha_{n}\left\|x_{n}-p\right\|^{2}+\left(1-\alpha_{n}\right)\left\|u_{n}-p\right\|^{2} \\
& \leq \alpha_{n}\left\|x_{n}-p\right\|^{2}+\left(1-\alpha_{n}\right)\left\|v_{n}-p\right\|^{2} \\
& \leq\left\|x_{n}-p\right\|^{2}-\left(1-\alpha_{n}\right) \sum_{m=1}^{\infty} \delta_{n, m}\left\|z_{n, m}-x_{n}\right\|^{2} .
\end{aligned}
$$


This implies that $\left(1-\alpha_{n}\right) \delta_{n, m}\left\|z_{n, m}-x_{n}\right\|^{2} \leq\left\|x_{n}-p\right\|^{2}-\left\|x_{n+1}-p\right\|^{2}$. In view of the restrictions (a) and (c), we find that

$$
\lim _{n \rightarrow \infty}\left\|z_{n, m}-x_{n}\right\|=0
$$

Let $T$ be the maximal monotone mapping defined by

$$
T x= \begin{cases}A x+N_{C} x, & x \in C, \\ \emptyset, & x \notin C .\end{cases}
$$

For any given $(x, y) \in G(T)$, we have $y-A x \in N_{C} x$. So, we have $\langle x-m, y-A x\rangle \geq 0$, for all $m \in C$. On the other hand, we have $u_{n}=\operatorname{Proj}_{C}\left(v_{n}-\lambda_{n} A y_{n}\right)$. We obtain

$$
\left\langle x-u_{n}, \frac{u_{n}-v_{n}}{\lambda_{n}}+A y_{n}\right\rangle \geq 0 .
$$

In view of the monotonicity of $A$, we see that

$$
\begin{aligned}
\left\langle x-u_{n_{i}}, y\right\rangle \geq & \left\langle x-u_{n_{i}}, A x\right\rangle \\
\geq & \left\langle x-u_{n_{i}}, A x\right\rangle-\left\langle x-u_{n_{i}}, \frac{u_{n_{i}}-v_{n_{i}}}{\lambda_{n_{i}}}+A y_{n_{i}}\right\rangle \\
= & \left\langle x-u_{n_{i}}, A x-A u_{n_{i}}\right\rangle+\left\langle x-u_{n_{i}}, A u_{n_{i}}-A y_{n_{i}}\right\rangle \\
& -\left\langle x-u_{n_{i}}, \frac{u_{n_{i}}-v_{n_{i}}}{\lambda_{n_{i}}}\right\rangle \\
\geq & \left\langle x-u_{n_{i}}, A u_{n_{i}}-A y_{n_{i}}\right\rangle-\left\langle x-u_{n_{i}}, \frac{u_{n_{i}}-v_{n_{i}}}{\lambda_{n_{i}}}\right\rangle
\end{aligned}
$$

in view of $\left\|v_{n}-x_{n}\right\| \leq \sum_{m=1}^{\infty} \delta_{n, m}\left\|z_{n, m}-x_{n}\right\|$. It follows from (2.5) that $\lim _{n \rightarrow \infty}\left\|v_{n}-x_{n}\right\|=0$. Notice that $\left\|u_{n}-x_{n}\right\| \leq\left\|u_{n}-v_{n}\right\|+\left\|v_{n}-x_{n}\right\|$. It follows that

$$
\lim _{n \rightarrow \infty}\left\|u_{n}-x_{n}\right\|=0
$$

This in turn implies that $u_{n_{i}} \rightarrow \xi$. It follows that $\langle x-\xi, y\rangle \geq 0$. Notice that $T$ is maximal monotone and hence $0 \in T \xi$. This shows from Lemma 1.3 that $\xi \in \operatorname{VI}(C, A)$.

Step 3. Show that $\xi \in \operatorname{GMEP}\left(F_{m}, B_{m}, \varphi_{m}\right)$.

It follows from (2.5) that $\left\{z_{n_{i}, m}\right\}$ converges weakly to $\xi$ for each $m \geq 1$. Since $z_{n, m}=$ $T_{r_{n, m}} x_{n}$, we have

$$
G_{m}\left(z_{n, m}, z\right)+\frac{1}{r_{n, m}}\left\langle z-z_{n, m}, z_{n, m}-x_{n}\right\rangle \geq 0, \quad \forall z \in C .
$$

From the assumption (A2), we see that

$$
\left\langle z-z_{n_{i}, m}, \frac{z_{n_{i}, m}-x_{n_{i}}}{r_{n_{i}, m}}\right\rangle \geq G_{m}\left(z, z_{n_{i}, m}\right), \quad \forall z \in C .
$$

In view of the assumption (A4), we find from (2.5) that $G_{m}(z, \xi) \leq 0, \forall z \in C$. For $t_{m}$ with $0<t_{m} \leq 1$ and $z \in C$, let $z_{t_{m}}=t_{m} z+\left(1-t_{m}\right) \xi$, for each $1 \leq m \leq N$. Since $z \in C$ and $\xi \in C$, 
we have $z_{t_{m}} \in C$. It follows that $G_{m}\left(z_{t_{m}}, \xi\right) \leq 0$. Notice that

$$
0=G_{m}\left(z_{t_{m}}, z_{t_{m}}\right) \leq t_{m} G_{m}\left(z_{t_{m}}, z\right)+\left(1-t_{m}\right) G_{m}\left(z_{t_{m}}, \xi\right) \leq t_{m} G_{m}\left(z_{t_{m}}, z\right)
$$

which yields $G_{m}\left(z_{t_{m}}, z\right) \geq 0, \forall z \in C$. Letting $t_{m} \downarrow 0$, one sees that $G_{m}(\xi, z) \geq 0, \forall z \in C$. This implies that $\xi \in \operatorname{GMEP}\left(F_{m}, B_{m}, \varphi_{m}\right)$ for each $m \geq 1$. This proves that $\xi \in \bigcap_{m=1}^{\infty} \operatorname{GMEP}\left(F_{m}\right.$, $\left.B_{m}, \varphi_{m}\right)$.

Step 4. Show that $\xi \in F(S)$.

Since $\lim _{n \rightarrow \infty}\left\|x_{n}-p\right\|$ exists, we put $\lim _{n \rightarrow \infty}\left\|x_{n}-p\right\|=d>0$. It follows that

$$
\lim _{n \rightarrow \infty}\left\|x_{n+1}-p\right\|=\lim _{n \rightarrow \infty}\left\|\alpha_{n}\left(x_{n}-p\right)+\left(1-\alpha_{n}\right)\left(S_{n} u_{n}-p\right)\right\|=d .
$$

Notice that $\lim \sup _{n \rightarrow \infty}\left\|S_{n} u_{n}-p\right\| \leq d$. From Lemma 1.5, we see that

$$
\lim _{n \rightarrow \infty}\left\|x_{n}-S_{n} u_{n}\right\|=0
$$

Since

$$
\begin{aligned}
\left\|S_{n} x_{n}-x_{n}\right\| & \leq\left\|S_{n} x_{n}-S_{n} u_{n}\right\|+\left\|S_{n} u_{n}-x_{n}\right\| \\
& \leq\left\|x_{n}-u_{n}\right\|+\left\|S_{n} u_{n}-x_{n}\right\|,
\end{aligned}
$$

we find from (2.6) and (2.7) that

$$
\lim _{n \rightarrow \infty}\left\|x_{n}-S_{n} x_{n}\right\|=0
$$

In view of $\left\|S x_{n}-x_{n}\right\| \leq\left\|S x_{n}-S_{n} x_{n}\right\|+\left\|S_{n} x_{n}-x_{n}\right\|$, we find from (2.8) that $\lim _{n \rightarrow \infty} \| x_{n}-$ $S x_{n} \|=0$. This implies from Lemma 1.6 that $\xi \in F(S)$. This completes the proof that $\xi \in \mathcal{F}$.

Step 5 . Show that the whole sequence $\left\{x_{n}\right\}$ weakly converges to $\xi$.

Let $\left\{x_{n_{j}}\right\}$ be another subsequence of $\left\{x_{n}\right\}$ converging weakly to $\xi^{\prime}$, where $\xi^{\prime} \neq \xi$. In the same way, we can show that $\xi^{\prime} \in \mathcal{F}$. Since the space $H$ enjoys Opial's condition, we, therefore, obtain

$$
\begin{aligned}
d & =\liminf _{i \rightarrow \infty}\left\|x_{n_{i}}-\xi\right\|<\liminf _{i \rightarrow \infty}\left\|x_{n_{i}}-\xi^{\prime}\right\| \\
& =\liminf _{j \rightarrow \infty}\left\|x_{j}-\xi^{\prime}\right\|<\liminf _{j \rightarrow \infty}\left\|x_{j}-\xi\right\|=d .
\end{aligned}
$$

This is a contradiction. Hence $\xi=\xi^{\prime}$. This completes the proof.

\section{Applications}

In this section, we consider solutions of the mixed equilibrium problem (1.3), which includes the Ky Fan inequality as a special case.

The so-called mixed equilibrium problem is to find $p \in C$ such that

$$
F(p, y)+\varphi(y)-\varphi(z) \geq 0, \quad \forall y \in C .
$$

The mixed equilibrium problem includes the Ky Fan inequality, fixed point problems, saddle problems, and complementary problems as special cases. 
Theorem 3.1 Let $C$ be a nonempty, closed, and convex subset of $H, S: C \rightarrow C$ a $\kappa$-strictly pseudocontractive mapping with a nonempty fixed point set, and $A: C \rightarrow H$ a L-Lipschitz continuous and monotone mapping. Let $F_{m}$ be a bifunction from $C \times C$ to $\mathbb{R}$ which satisfies (A1)-(A4), and $\varphi_{m}: C \rightarrow \mathbb{R}$ a lower semicontinuous and convex function for each $m \geq 1$. Assume that $\mathcal{F}:=\bigcap_{m=1}^{\infty} \operatorname{MEP}\left(F_{m}, \varphi_{m}\right) \cap \operatorname{VI}(C, A) \cap F(S)$ is not empty. Let $\left\{\alpha_{n}\right\},\left\{\beta_{n}\right\}$ and $\left\{\delta_{n, m}\right\}$ be real number sequences in $(0,1)$. Let $\left\{\lambda_{n}\right\},\left\{r_{n, m}\right\}$ be positive real number sequences. Let $\left\{x_{n}\right\}$ be a sequence generated in the following manner:

$$
\left\{\begin{array}{l}
x_{1} \in H, \\
x_{n+1}=\alpha_{n} x_{n}+\left(1-\alpha_{n}\right)\left(\beta_{n} I+\left(1-\beta_{n}\right) S\right) \operatorname{Proj}_{C}\left(\sum_{m=1}^{\infty} \delta_{n, m} z_{n, m}-\lambda_{n} A y_{n}\right), \quad n \geq 1, \\
y_{n}=\operatorname{Proj}_{C}\left(\sum_{m=1}^{\infty} \delta_{n, m} z_{n, m}-\lambda_{n} A \sum_{m=1}^{\infty} \delta_{n, m} z_{n, m}\right),
\end{array}\right.
$$

where $z_{n, m}$ is such that

$$
F_{m}\left(z_{n, m}, z\right)+\varphi_{m}(z)-\varphi_{m}\left(z_{n, m}\right)+\frac{1}{r_{n, m}}\left\langle z-z_{n, m}, z_{n, m}-x_{n}\right\rangle \geq 0, \quad \forall z \in C .
$$

Assume that $\left\{\alpha_{n}\right\},\left\{\beta_{n}\right\},\left\{\delta_{n, m}\right\},\left\{\lambda_{n}\right\},\left\{r_{n, m}\right\}$ satisfy the following restrictions:

(a) $0<a \leq \alpha_{n} \leq b<1$;

(b) $\kappa \leq \beta_{n} \leq c<1$;

(c) $\sum_{m=1}^{\infty} \delta_{n, m}=1$, and $0<d \leq \delta_{n, m} \leq 1$;

(d) $\liminf _{n \rightarrow \infty} r_{n, m}>0$ and $e \leq \lambda_{n} \leq f$, where $e, f \in(0,1 / L)$.

Then the sequence $\left\{x_{n}\right\}$ weakly converges to some point $\bar{x} \in \mathcal{F}$.

Proof If $B_{m}=0$, we draw the desired conclusion immediately from Theorem 2.1.

Further, if $S$ is nonexpansive, we find from Theorem 3.1 the following result.

Corollary 3.2 Let C be a nonempty, closed, and convex subset of $H, S: C \rightarrow C$ a nonexpansive mapping with a nonempty fixed point set, and $A: C \rightarrow H$ an L-Lipschitz continuous and monotone mapping. Let $F_{m}$ be a bifunction from $C \times C$ to $\mathbb{R}$ which satisfies (A1)-(A4), and $\varphi_{m}: C \rightarrow \mathbb{R}$ a lower semicontinuous and convex function for each $m \geq 1$. Assume that $\mathcal{F}:=\bigcap_{m=1}^{\infty} \operatorname{MEP}\left(F_{m}, \varphi_{m}\right) \cap \operatorname{VI}(C, A) \cap F(S)$ is not empty. Let $\left\{\alpha_{n}\right\},\left\{\beta_{n}\right\}$, and $\left\{\delta_{n, m}\right\}$ be real number sequences in $(0,1)$. Let $\left\{\lambda_{n}\right\},\left\{r_{n, m}\right\}$ be positive real number sequences. Let $\left\{x_{n}\right\}$ be a sequence generated in the following manner:

$$
\left\{\begin{array}{l}
x_{1} \in H, \\
x_{n+1}=\alpha_{n} x_{n}+\left(1-\alpha_{n}\right) S \operatorname{Proj}_{C}\left(\sum_{m=1}^{\infty} \delta_{n, m} z_{n, m}-\lambda_{n} A y_{n}\right), \quad n \geq 1, \\
y_{n}=\operatorname{Proj}_{C}\left(\sum_{m=1}^{\infty} \delta_{n, m} z_{n, m}-\lambda_{n} A \sum_{m=1}^{\infty} \delta_{n, m} z_{n, m}\right),
\end{array}\right.
$$

where $z_{n, m}$ is such that

$$
F_{m}\left(z_{n, m}, z\right)+\varphi_{m}(z)-\varphi_{m}\left(z_{n, m}\right)+\frac{1}{r_{n, m}}\left\langle z-z_{n, m}, z_{n, m}-x_{n}\right\rangle \geq 0, \quad \forall z \in C .
$$

Assume that $\left\{\alpha_{n}\right\},\left\{\beta_{n}\right\},\left\{\delta_{n, m}\right\},\left\{\lambda_{n}\right\},\left\{r_{n, m}\right\}$ satisfy the following restrictions:

(a) $0<a \leq \alpha_{n} \leq b<1$; 
(b) $\sum_{m=1}^{\infty} \delta_{n, m}=1$, and $0<d \leq \delta_{n, m} \leq 1$;

(c) $\liminf _{n \rightarrow \infty} r_{n, m}>0$ and $e \leq \lambda_{n} \leq f$, where $e, f \in(0,1 / L)$.

Then the sequence $\left\{x_{n}\right\}$ weakly converges to some point $\bar{x} \in \mathcal{F}$.

If $A=0$, we find from Theorem 2.1 the following result.

Theorem 3.3 Let $C$ be a nonempty, closed, and convex subset of $H, S: C \rightarrow C$ a $\kappa$-strictly pseudocontractive mapping with a nonempty fixed point set. Let $F_{m}$ be a bifunction from $C \times C$ to $\mathbb{R}$ which satisfies (A1)-(A4), $B_{m}: C \rightarrow H$ a continuous and monotone mapping, $\varphi_{m}: C \rightarrow \mathbb{R}$ a lower semicontinuous and convex function for each $m \geq 1$. Assume that $\mathcal{F}:=\bigcap_{m=1}^{\infty} \operatorname{GMEP}\left(F_{m}, B_{m}, \varphi_{m}\right) \cap F(S)$ is not empty. Let $\left\{\alpha_{n}\right\},\left\{\beta_{n}\right\}$, and $\left\{\delta_{n, m}\right\}$ be real number sequences in $(0,1)$. Let $\left\{r_{n, m}\right\}$ be a positive real number sequence. Let $\left\{x_{n}\right\}$ be a sequence generated in the following manner:

$$
x_{1} \in H, \quad x_{n+1}=\alpha_{n} x_{n}+\left(1-\alpha_{n}\right)\left(\beta_{n} I+\left(1-\beta_{n}\right) S\right) \sum_{m=1}^{\infty} \delta_{n, m} z_{n, m}, \quad n \geq 1,
$$

where $z_{n, m}$ is such that

$$
F_{m}\left(z_{n, m}, z\right)+\left\langle B_{m} z_{n, m}, z-z_{n, m}\right\rangle+\varphi_{m}(z)-\varphi_{m}\left(z_{n, m}\right)+\frac{1}{r_{n, m}}\left\langle z-z_{n, m}, z_{n, m}-x_{n}\right\rangle \geq 0, \quad \forall z \in C .
$$

Assume that $\left\{\alpha_{n}\right\},\left\{\beta_{n}\right\},\left\{\delta_{n, m}\right\}$, and $\left\{r_{n, m}\right\}$ satisfy the following restrictions:

(a) $0<a \leq \alpha_{n} \leq b<1$;

(b) $\kappa \leq \beta_{n} \leq c<1$;

(c) $\sum_{m=1}^{\infty} \delta_{n, m}=1$, and $0<d \leq \delta_{n, m} \leq 1$;

(d) $\liminf _{n \rightarrow \infty} r_{n, m}>0$.

Then the sequence $\left\{x_{n}\right\}$ weakly converges to some point $\bar{x} \in \mathcal{F}$.

\section{Competing interests}

The authors declare that they have no competing interests.

\section{Authors' contributions}

All authors contributed equally to this manuscript. All authors read and approved the final manuscript.

\section{Author details}

${ }^{1}$ School of Information Engineering, North China University of Water Resources and Electric Power, Zhengzhou, Henan 450011, China. ${ }^{2}$ School of Mathematics and Information Science, North China University of Water Resources and Electric Power, Zhengzhou, Henan 450011, China.

\section{Acknowledgements}

The authors are grateful to the reviewers for useful suggestions which improved the contents of the article.

Received: 14 January 2014 Accepted: 8 May 2014 Published: 22 May 2014

\section{References}

1. Fan, K: A minimax inequality and its application. In: Shisha, O (ed.) Inequalities, vol. 3, pp. 103-113. Academic Press, New York (1972)

2. Blum, E, Oettli, W: From optimization and variational inequalities to equilibrium problems. Math. Stud. 63, 123-145 (1994)

3. Cho, SY, Qin, X: On the strong convergence of an iterative process for asymptotically strict pseudocontractions and equilibrium problems. Appl. Math. Comput. 235, 430-438 (2014)

4. Park, S: A review of the KKM theory on $\phi_{A}$-space or GFC-spaces. Adv. Fixed Point Theory 3, 355-382 (2013)

5. Combettes, PL, Hirstoaga, SA: Equilibrium programming in Hilbert spaces. J. Nonlinear Convex Anal. 6, 117-136 (2005)

6. Qin, X, Agarwal, RP: Shrinking projection methods for a pair of asymptotically quasi- $\boldsymbol{\phi}$-nonexpansive mappings. Numer. Funct. Anal. Optim. 31, 1072-1089 (2010) 
7. Rodjanadid, B, Sompong, S: A new iterative method for solving a system of generalized equilibrium problems, generalized mixed equilibrium problems and common fixed point problems in Hilbert spaces. Adv. Fixed Point Theory 3, 675-705 (2013)

8. Cho, SY, Li, W, Kang, SM: Convergence analysis of an iterative algorithm for monotone operators. J. Inequal. Appl. 2013, Article ID 199 (2013)

9. Cho, SY, Qin, X, Kang, SM: Iterative processes for common fixed points of two different families of mappings with applications. J. Glob. Optim. 57, 1429-1446 (2013)

10. Qin, X, Chang, SS, Cho, YJ: Iterative methods for generalized equilibrium problems and fixed point problems with applications. Nonlinear Anal., Real World Appl. 11, 2963-2972 (2010)

11. Zegeye, $\mathrm{H}$, Shahzad, $\mathrm{N}$ : Strong convergence theorem for a common point of solution of variational inequality and fixed point problem. Adv. Fixed Point Theory 2, 374-397 (2012)

12. Chen, JH: Iterations for equilibrium and fixed point problems. J. Nonlinear Funct. Anal. 2013, Article ID 4 (2013)

13. Yuan, Q, Cho, SY: Proximal point algorithms for zero points of nonlinear operators. Fixed Point Theory Appl. 2014, Article ID 42 (2014)

14. He, RH: Coincidence theorem and existence theorems of solutions for a system of Ky Fan type minimax inequalities in FC-spaces. Adv. Fixed Point Theory 2, $47-57$ (2012)

15. Cho, SY, Kang, SM, Cho, SY, Kang, SM: Approximation of common solutions of variational inequalities via strict pseudocontractions. Acta Math. Sci. 32, 1607-1618 (2012)

16. Qin, $X, C h o, S Y, W a n g, L: A$ regularization method for treating zero points of the sum of two monotone operators, Fixed Point Theory Appl. 2014, Article ID 75 (2014)

17. Kim, JK, Anh, PN, Nam, YM: Strong convergence of an extended extragradient method for equilibrium problems and fixed point problems. J. Korean Math. Soc. 49, 187-200 (2012)

18. Qin, X, Cho, YJ, Kang, SM: Convergence theorems of common elements for equilibrium problems and fixed point problems in Banach spaces. J. Comput. Appl. Math. 225, 20-30 (2009)

19. Kim, JK: Strong convergence theorems by hybrid projection methods for equilibrium problems and fixed point problems of the asymptotically quasi- $\phi$-nonexpansive mappings. Fixed Point Theory Appl. 2011, Article ID 10 (2011)

20. Qin, X, Cho, SY, Kang, SM: Strong convergence of shrinking projection methods for quasi- $\phi$-nonexpansive mappings and equilibrium problems. J. Comput. Appl. Math. 234, 750-760 (2010)

21. Browder, FE, Petryshyn, WV: Construction of fixed points of nonlinear mappings in Hilbert spaces. J. Math. Anal. Appl. 20, 197-228 (1967)

22. Qin, X, Cho, SY, Kang, SM: An extragradient-type method for generalized equilibrium problems involving strictly pseudocontractive mappings. J. Glob. Optim. 49, 679-693 (2011)

23. Cheng, $\mathrm{P}, \mathrm{Wu}, \mathrm{H}$ : On asymptotically strict pseudocontractions and equilibrium problems. J. Inequal. Appl. 2013 Article ID 251 (2013)

24. Jung, JS: Iterative methods for mixed equilibrium problems and strictly pseudocontractive mappings. Fixed Point Theory Appl. 2012, Article ID 184 (2012)

25. Cho, SY, Kang, SM: Approximation of fixed points of pseudocontraction semigroups based on a viscosity iterative process. Appl. Math. Lett. 24, 224-228 (2011)

26. Qin, X, Shang, M, Kang, SM: Strong convergence theorems of modified Mann iterative process for strict pseudo-contractions in Hilbert spaces. Nonlinear Anal. 70, 1257-1264 (2009)

27. Kim, JK, Buong, N: A new iterative method for equilibrium problems and fixed point problems for infinite family of nonself strictly pseudocontractive mappings. Fixed Point Theory Appl. 2013, Article ID 286 (2013)

28. Cho, SY, Qin, X, Wang, L: Strong convergence of a splitting algorithm for treating monotone operators. Fixed Point Theory Appl. 2014, Article ID 94 (2014)

29. Wang, G, Sun, S: Hybrid projection algorithms for fixed point and equilibrium problems in a Banach space. Adv. Fixed Point Theory 3, 578-594 (2013)

30. Rockafellar, RT: On the maximality of sums of nonlinear monotone operators. Trans. Am. Math. Soc. 149, 75-88 (1970)

31. Yang, L, Zhao, F, Kim, JK: Hybrid projection method for generalized mixed equilibrium problem and fixed point problem of infinite family of asymptotically quasi- $\phi$-nonexpansive mappings in Banach spaces. Appl. Math. Comput. $218,6072-6082$ (2012)

32. Schu, J: Weak and strong convergence of fixed points of asymptotically nonexpansive mappings. Bull. Aust. Math. Soc. 43, 153-159 (1991)

33. Tan, KK, Xu, HK: Approximating fixed points of nonexpansive mappings by the Ishikawa iterative process. J. Math. Anal. Appl. 178, 301-308 (1993)

10.1186/1029-242X-2014-203

Cite this article as: Li and Zhao: On variational inequality, fixed point and generalized mixed equilibrium problems. Journal of Inequalities and Applications 2014, 2014:203 